\title{
Towards sustainable urban development: traffic generation at food superstores in the UK
}

\author{
C. Black ${ }^{1}$, D. C. Broadstock ${ }^{2}$, A. Collins ${ }^{3}$ \& L. C. Hunt ${ }^{2}$ \\ ${ }^{1} J M P$ Consultants Ltd., London, UK \\ ${ }^{2}$ Surrey Energy Economics Centre (SEEC), University of Surrey, UK \\ ${ }^{3}$ Department of Economics, University of Portsmouth, UK
}

\begin{abstract}
In the light of increasing concern over home-shopping traffic growth generated by food superstores in the UK and elsewhere and their possible role in reinforcing a 'food desert' effect, this study introduces an empirical framework to help underpin subsequent policy decisions. A trip attraction model is estimated by ordinary least squares (OLS) for food superstores in the UK using a composite dataset constructed from data from the UK Census of Population, the UK National Online Manpower Information System (NOMIS), and the Trip Rate Information Computer System (TRICS).

It is found that traffic to a given food superstore, other things being equal, increases with car ownership, parking provision, retail floor space, distance to the nearest competitor and, perhaps surprisingly, increased public transport provision. The latter effect is discussed in the light of a possible explanation linked to the 'food deserts' debate, along with the associated implications for effective (inner-urban) sustainable development. Increases in household size are found to be associated with a fall in vehicle traffic to a site, due to household economies of scope and scale, which may also perpetuate use of less sustainable modes of transport.
\end{abstract}

Keywords: traffic generation, transport planning, food superstores, food deserts, activity based travel, sustainable development.

\section{Introduction}

Society's increasing reliance on food superstores and their associated growth and spatial placement are the subject of considerable controversy and debate in 
the UK and elsewhere (see, for example, Yim [1]; Clarke et al. [2]; Smith and Sanchez [3]). This issue has highlighted concerns relating to the encouragement of traffic growth on local road networks (with all its attendant negative externalities of emissions, congestion, higher accident rates etc.) and the deleterious effects food superstores may have for the trading vitality, and the continuing investment in physical fabric and vibrancy of traditional inner urban shopping centres. The food superstore phenomenon has also been accused of being a central element in the development of 'food deserts' in some parts of the UK, i.e., areas where access to food shops is difficult for low income households and where there is a lack of small retail shops to meet the demand for healthy, affordable food (for example see Wrigley [4]). Thus, the problems identified with food superstores relate both to their role in traffic generation and to their role in the development of a less sustainable urban spatial structure.

This study contributes to this issue by estimating a trip attraction model for food superstores in the United Kingdom, utilizing data from the Trip Rate Information Computer System (TRICS [5]) database from the period 1986-2003 augmented with data from the UK Census and other data sources, providing a rich dataset from which the model estimates are generated. This research is (as far as known) the first to combine TRICS [5] data with these other data sources for analysis beyond the arena of local planning and development control (see Black et al. [6] for more details).

The paper is organised as follows. In the next section the modelling strategy is developed and explained with the data described in the following section. Section 4 presents and discusses the results, with the final section offering a summary and concluding remarks.

\section{Modelling strategy and estimation}

It is widely understood that the demand for transport is a derived demand stemming primarily from the desire to participate in activities or to purchase goods (see for example Ettema and Timmermans [7] or Hensher and Button [8]). An Activity-Based Trip Model is therefore specified under the same auspices as a standard demand relationship for consumer behaviour, derived from standard micro-economics so that the demand for a good or service is determined by the desire and ability to purchase the good (e.g. characteristics of the good, and individual capacity to consume), as well as interactions with substitute markets/goods and/or effects. This can be summarised as follows:

$$
\begin{gathered}
T_{m, o . d}=f\left(E_{o}, S E_{o}, P_{d}, G_{d}\right) \\
m \ni M, o \ni O, d \ni D
\end{gathered}
$$

where ' $\mathrm{M}$ ' is the set of travel modes, ' $\mathrm{O}$ ' is the set of origins and ' $\mathrm{D}$ ' is the set of destinations. 
Equation (1) implies that the desire to travel to a site (by any chosen mode of travel, for instance driving, cycling, walking or taking public transport), is determined by factors that influence the ability and/or wish to partake in (or consume) the activity (or service) which that site offers. In particular, 'E' represents the economic characteristics of the local population, thus capturing the ability of individuals within that area to consume. ' $\mathrm{P}$ ' is site specific attributes, which may be considered as features of that site which may serve to attract more trips. The variable ' $G$ ' suggests that wider geographic information may have some bearing on trip levels including site accessibility, and potential resistance offered by the existing geography. Finally 'SE' are socio-economic characteristics, which reflect (in part) lifestyles, and consequently, consumption choices within a given area. Previous multivariate trip generation models adopting similar relationships have been advocated by, for example, Hensher and Dalvi [9] and Washington [10] although the inclusion of physical characteristics of a site is not often introduced, probably due to the nature of the datasets used in previous works. The dependant variable ' $\mathrm{T}$ ' in this instance, is the volume of traffic,

A number of simplifying assumptions are required to constrain the analysis to an easily manageable selection of data, as follows;

- ' $\mathrm{M}$ ' is constrained to passenger vehicle traffic only.

- ' $\mathrm{O}$ ' is not known with certainty, and is therefore assumed to be a function of the surrounding areas characteristics.

- ' $\mathrm{D}$ ' is constrained to one type of destination, in this instance food superstores. i.e., the model estimates the level of trips for only one individual type of activity.

The traffic count data is typically from established sites (i.e. not new developments), it is therefore assumed that the general customer base has levelled out after any initial opening 'boom', where the customer levels are essentially stable. It is not difficult to formulate hypotheses to suggest that initial opening levels could be (and are likely to be) higher or lower than the estimates produced by the static model. Although initial opening levels should, on average, converge towards the model estimates over time. The estimated model does not differentiate between trips to the store from linked (or chained) trips or single purpose journeys. The framework therefore focuses on the fundamentals of the determinants of trip 'attractions' to a particular site.

Given the discussion, the results of this study are based upon the following general (log-linear) specification;

$$
\begin{aligned}
& \ln F L O W_{i}=\beta_{0}+\beta_{1}\left(\ln C A R_{i}\right)+\beta_{2}\left(\ln A C C E S S I B I L I T Y_{i}\right)+\beta_{3}\left(D A T E_{i}\right) \\
& \beta_{4}(\ln \text { FLOORSPACE } *)+\beta_{5}\left(\ln \text { RESISTANCE }_{i}\right)+\beta_{6}(\ln A V H S)+ \\
& \beta_{7}\left(\ln E M P_{i}\right)+\beta_{8}\left(\ln P A R K I N G_{i}\right)+\beta_{9}\left(P F S_{i}\right)+\beta_{j}\left(L U_{m, i}\right)+ \\
& \beta_{17}\left(E C O N O M Y_{i}\right)+\beta_{18}\left(S A T_{i}\right)+\beta_{19}\left(S U N_{i}\right)+\beta_{20}\left(M O N-\text { THURS }_{i}\right)+\mu_{i}
\end{aligned}
$$


For $j=(m+8)$ where $m=1, \ldots, 7$ and $i=1, \ldots, N . N$ is the number of observations in the dataset.

Where FLOW = The average hourly flow of passenger vehicle traffic to site $i$.

$\begin{array}{ll}\text { CAR } & =\text { Car ownership in the area of site } i . \\ \text { ACCESSIBILITY } & =\text { Public service provision at site } i . \\ \text { DATE } & =\text { Date of the survey for site } i . \\ & \text { Two alternatives are available } \\ & \text { GFA= Gross Floor Area for site } i . \\ & \text { RFA= Retail Floor Area for site } i . \\ \text { RESISTANCE } & =\text { Proxy for competition. } \\ \text { AVHS } & =\text { Measure of the socioeconomic characteristics } \\ \text { EMP } & \text { of the area surrounding site } i . \\ \text { PARKING } & =\text { Employment levels in the area of site } i . \\ \text { PFS } & =\text { On site parking at site } i . \\ \text { LU1-LU7 } & =\text { Petrol pump facilities. } \\ \text { ECONOMY } & =\text { Land-zone indicators. } \\ \text { SAT } & =\text { Quality proxy. } \\ \text { SUN } & =\text { Day identifier. } \\ \text { MON-THURS } & =\text { Day identifier. } \\ \text { ln } & =\text { Day identifier. } \\ \beta_{0} & =\text { Natural logarithm. } \\ \beta_{1, \ldots, 20} & =\text { Constant or intercept term. } \\ \mu_{i} & =\text { Estimated slope coefficients. } \\ & =\text { Residual term. }\end{array}$

and $a$-priori the following are expected for the slope coefficients, $\beta_{0}>0, \beta_{1}>0$, $\beta_{2}<0, \beta_{3}>0, \beta_{4}>0, \beta_{5}>0, \beta_{6}<0, \beta_{7}>0, \beta_{8}>0, \beta_{9}>0, \beta_{17}<0, \beta_{18}>0, \beta_{19}<0, \beta_{20}<0$, No prior expectations are made on the coefficients of the land zone dummies $\left(\beta_{10}\right.$ $\ldots \beta_{16)}$. The model is estimated using Ordinary Least Squares (OLS) and given the logarithmic specification the estimated coefficients represent constant elasticities.

The expectation of a negative coefficient on the variable AVHS may not be intuitively obvious without some clarification. The expectation is that household levels of economies of scale and scope exist such that "...the cost per person of maintaining a given material standard of living may fall as household size rises..." (Nelson [11], p 1301). Such economies of scale in a non-nuclear household could be considered as economies of scope, when two independent parties (i.e. two individuals living in shared accommodation) are able to pool together their resources and reduce the marginal cost faced by each in achieving the same level of utility. Nelson [11] further revealed in the context of US food shopping, that for households choosing to pool their resources 2 people can essentially live for the price of 1.19 people. 
Following this reasoning, it is contended that the number of trips to a food store are negatively related to household size (irrespective of binding household parking constraints which may also contribute to this effect). Further, larger households will also likely exhibit more diverse characteristics in their modal choices, i.e. as household size increases, the probability that one of the household members will prefer a non-car mode of travel to a food store also increases.

Table 1: $\quad$ Source and description for the variables.

\begin{tabular}{|c|c|c|}
\hline Variable & Description & Data Source \\
\hline FLOW & Average hourly flow of cars & TRICS \\
\hline CAR & $\begin{array}{l}\text { Average household car ownership for } \\
\text { the area }\end{array}$ & TRICS \\
\hline ACCESSIBILITY & $\begin{array}{l}\text { A measure of public service } \\
\text { accessibility (bus services) at the site }\end{array}$ & TRICS \\
\hline DATE & Date variable & TRICS \\
\hline GFA & Gross Floor Area & TRICS \\
\hline RFA & Retail Floor Area & TRICS \\
\hline RESISTANCE & $\begin{array}{l}\text { A measure of spatial resistance (via } \\
\text { proximity to nearest similar competitor) }\end{array}$ & TRICS \\
\hline AVHS & Average Household size & CENSUS/NOMIS \\
\hline EMP & $\begin{array}{l}\text { Average household employment for the } \\
\text { area }\end{array}$ & CENSUS/NOMIS \\
\hline PARKING & Total parking provision for the site & TRICS \\
\hline PFS & $\begin{array}{l}\text { Does the site have a petrol station } \\
\text { (1=yes) }\end{array}$ & TRICS \\
\hline LU1 & Commercial zone & TRICS \\
\hline LU2 & Edge of town & TRICS \\
\hline LU3 & Edge of town centre & TRICS \\
\hline LU4 & Freestanding & TRICS \\
\hline LU5 & Industrial zone & TRICS \\
\hline LU6 & Neighbourhood zone & TRICS \\
\hline LU7 & Suburban area & TRICS \\
\hline Base & Town centre & TRICS \\
\hline ECONOMY & Is the Store 'less mainstream' (1=yes) & Author Specified \\
\hline SAT & Dummy variables identifying the day of & TRICS \\
\hline SUN & week & TRICS \\
\hline MON-THURS & & TRICS \\
\hline
\end{tabular}

\section{Data}

The data used in this survey has been extracted from three sources, namely the TRICS [5] database (Version 2004b), NOMIS [12] and the 2001 UK Census [13]. The TRICS database provides an unbalanced pseudo-panel (see Baltagi [14]) of traffic counts and site characteristics for various land use types (including food superstores) primarily with a view to informing planning policy and development control at the local level. The database is typically consulted to provide a guide of the expected traffic flows associated with any given new development and thus inform planning decisions, junction improvements and transport network management. Due to the restrictions on the available degrees 
of freedom for this land use, the data is restricted to a cross section for this study.

The variables considered in the analysis are described and defined in Table 1. The specific land use dummy variables introduced in this table (denoted (Base,LU1,..,LU7)) represent food superstores in specific types of geographical zones or locations as indicated in Planning Policy Guidance Note 13 DETR [15].

Table 2: $\quad$ Composite dataset descriptive statistics.

\begin{tabular}{|c|c|c|c|c|c|}
\hline \multicolumn{6}{|c|}{ Continuous variables } \\
\hline Variable & Number & mean & Std. Dev. & Min & $\operatorname{Max}$ \\
\hline CAR & 201 & -0.136 & 0.320 & -1.386 & 0.262 \\
\hline ACCESSIBILITY & 201 & 3.882 & 0.633 & 2.303 & 4.500 \\
\hline DATE & 201 & 1983.269 & 4.247 & 2003 & 1986 \\
\hline GFA & 201 & 8.565 & 0.400 & 7.097 & 9.218 \\
\hline RFA & 201 & 8.006 & 0.385 & 6.783 & 8.817 \\
\hline RESISTANCE & 201 & 1.120 & 0.866 & -1.386 & 3.367 \\
\hline AVHS & 201 & 0.861 & 0.527 & 0.759 & 0.977 \\
\hline EMPLOYMENT & 201 & 0.190 & 0.205 & -0.185 & 0.595 \\
\hline PARKING & 201 & 6.107 & 0.504 & 4.489 & 6.908 \\
\hline \multicolumn{6}{|l|}{ Dummy Variables } \\
\hline Variable & Number & Mean & Std. Dev & Median & \\
\hline PFS & 201 & 0.507 & 0.501 & & \\
\hline LU1 & 201 & 0.099 & 0.099 & & \\
\hline LU2 & 201 & 0.358 & 0.481 & & \\
\hline LU3 & 201 & 0.020 & 0.140 & & \\
\hline LU4 & 201 & 0.054 & 0.228 & & \\
\hline LU5 & 201 & 0.035 & 0.184 & & \\
\hline LU6 & 201 & 0.129 & 0.336 & & \\
\hline LU7 & 201 & 0.194 & 0.396 & & \\
\hline ECONOMY & 201 & 0.094 & 0.293 & & \\
\hline SATURDAY & 201 & 0.313 & 0.465 & & \\
\hline SUNDAY & 201 & 0.144 & 0.352 & & \\
\hline MON-THURS & 201 & 0.104 & 0.306 & & \\
\hline
\end{tabular}

In relation to the geographic extent of the observations around the UK, the coverage is dispersed around the country though largely concentrated, as is to be expected, around major urban conurbations. In particular the site data is concentrated within the North West of England, the Central Lowlands of Scotland and the Southern Coastal Belt of England. Table 2 summarises the data used to estimate equation (2).

\section{Results}

Given the two floor space variables available, two versions of equation (2) were estimated by OLS. The two estimated preferred models are summarised in Table 3 (I being for GFA and II for RFA). The variable DATE was always not 
significantly different from zero and hence omitted from the final model. This in itself suggests that, although over recent years there has been increasing growth in the number of superstores being used by food retailers (as opposed to smaller store sizes), this is not associated with statistically observable shifts in the fundamental behaviour of shoppers.

Table 3: $\quad$ Food superstore trip generation model estimates.

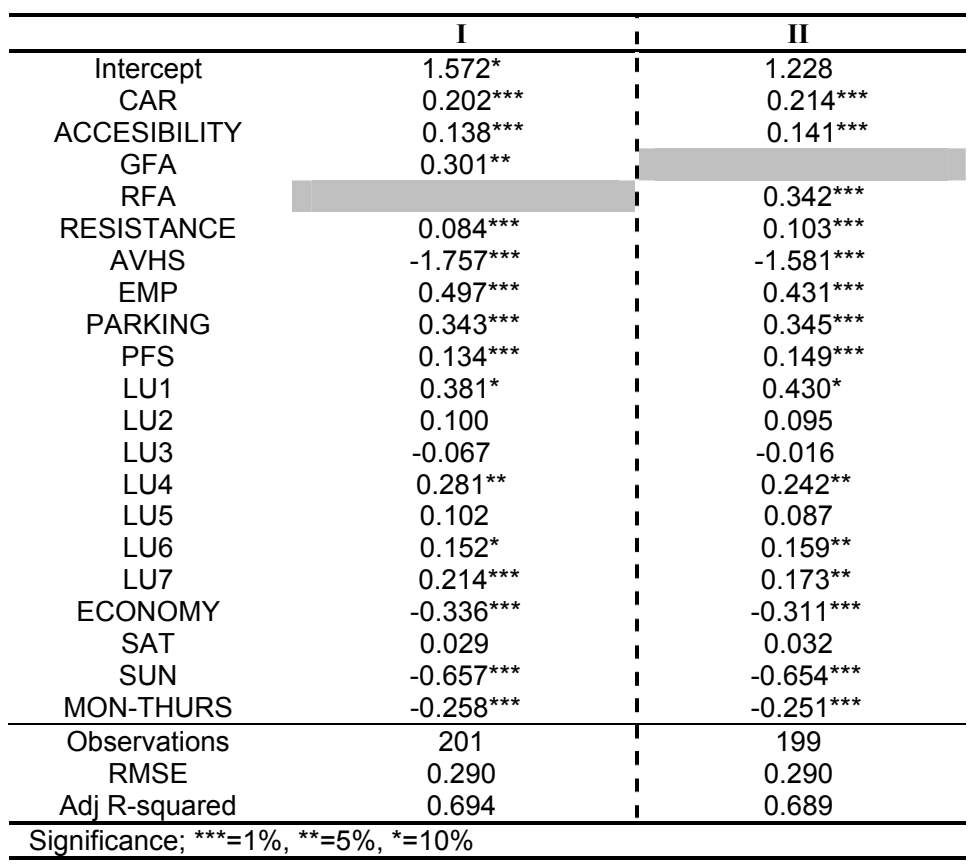

The results given in Table 3 are in accordance with a-priori expectations outlined in the previous section, although the coefficient on the public transport accessibility variable warrants further discussion (see below). In response to the debate surrounding the use of GFA or RFA in trip generation models (see for instance Tan and Fan [16] or Dasgupta et al. [17]), both are estimated for comparison. However, as shown in Table 3 there is no discernible difference between the estimated equations I and II (in terms of Adj R-squared, Root Mean Squared Error (RMSE), and the size and significance of the estimated parameters) illustrating the robustness of the results to the two different measures of floorspace. Consequently, subsequent qualitative discussion does not differentiate between model I and II (further specification tests of these models and their robustness can be found in Black et al. [6]).

The public transport variable provides what may at first be considered a counterintuitive result. The positive coefficient implies that as public service provision increases, so do trips to that site by car. This may simply identify a correlation between bus provision and large business centres, as large 
superstores may potentially attract higher rates of public service provision as the service providers realise that the large superstores are likely to offer a larger (and more profitable) customer base than the smaller food stores. If bus services were indeed being 'sucked' towards more profitable food superstore sites and away from serving other more traditional shopping areas, then this might be considered as contributing to the development of 'food deserts'.

Discussing policy with respect to public transport variable is overlaid by a desire to encourage increased levels of public transport use, in line with the social exclusion/mobility as well as the environmental agenda. The results suggest on face value that less provision for such services might be preferred as it is associated with lower car traffic levels. Perhaps a more reasonable explanation might simply be that public transport service providers are not providing adequate service levels at the origin end of the food superstore journey. If they were providing the level of service at the origin that people really wished to have, then one may find that the coefficient on this variable decreases and maybe could change sign altogether.

The rest of the coefficients follow standard micro-economic demand theory, and it is observed that floor space, distance to the nearest food superstore competition, household type and size, parking provision and the inclusion of a petrol filling station at a site all return positive coefficients. These variables generally reflect the ability to substitute the store for alternative shopping centres, and the costs involved with doing so.

\section{Summary and conclusion}

In the light of increasing concern over the external effects arising from traffic growth emanating from food superstore developments and the controversy over the role of such superstores in creating 'food deserts' in the UK, a trip attraction model for food superstores in the UK was estimated by OLS using traffic count and site specific data derived from the TRICS database augmented with data from the Census of Population and Nomis.

The results indicate among other things, that a $1 \%$ increase in car ownership, parking provision and floorspace increases trips by $0.2 \%, 0.3 \%$ and $0.3 \%$ respectively. Perhaps surprisingly, it is found that a $1 \%$ increase in bus services at a site leads to a $0.1 \%$ increase in trips to food superstores by cars, whilst a $1 \%$ increase in average household size leads to a $1.8 \%$ decrease in trips made to a food superstore by car.

The existence of scale and scope household economies in connection with food superstore trips found above suggests that communities with larger household sizes will naturally have a preference towards large food superstores. Therefore these stores are increasingly less likely to be placed in inner urban locations. These household scale and scope economies essentially help perpetuate and accentuate food desert concerns, as well as concerns with urban sprawl and poor progress in the development of sustainable communities. Such phenomena are, however, clearly not in the range of realistic direct policy 
variables that lie within the grasp of urban and transport planners in advanced urban economies.

As city space is at a premium, it may not be feasible for superstores to locate at inner urban locations in a way that adequately meets business requirements (i.e. to maximise their profits they wish to facilitate customer accessibility which, as the empirical results reveal, are greatly influenced by the level of parking provision). A further implication of this is that developers may then rationally show a preference towards outer urban areas, where it is easier to satisfy their parking ratio requirements. Thereby contributing to the genesis and maintenance of food deserts and hence inhibiting the development of sustainable communities.

\section{Acknowledgements}

This work represents initial work undertaken as part of on-going research collaboration between the Surrey Energy Economics Centre (SEEC) University of Surrey, the Department of Economics, University of Portsmouth and JMP Consulting Ltd. This is partly support by the UK Economic and Social Research Council (Project Number PTA-033-2004-00035) which is gratefully acknowledged, as is permission from JMP Consultants Ltd. and the UK TRICS Consortium, to use the TRICS database.

\section{References}

[1] Yim, Y. (1992), The Effects of Transportation Services on the Scale of Food Retailing, Working Paper, No 112, University of California Transportation Centre (UCTC).

[2] Clarke, I., Horita, M. and Mackaness, W. (2000), The Spatial Knowledge of Retail Decision Makers: Capturing and Interpreting Group Insight Using a Composite Cognitive Map, Chain, International Review of Retail, Distribution and Consumer Research 10(3), 265-285.

[3] Smith, L. and Sanchez, S. (2003), Assessment of Business Potential at Retail Sites: Empirical Findings from a US Supermarket Chain, International Review of Retail, Distribution and Consumer Research 13(1), 37-58.

[4] Wrigley, N. (2002), Food deserts in British cities: policy contexts and research priorities, Urban Studies 39, 2029-2040.

[5] TRICS 2004(b) Build 9.43 (2004), JMP Consulting Ltd. (see www.TRICS.org for further information)

[6] Black, C., Broadstock, D. C., Collins, A. and Hunt, L. C. (2006) Food Superstores, Food Deserts and Traffic Generation in the UK: A SemiParametric Regression Approach, Surrey Energy Economics Discussion Paper, SEED No. 112, March, www.seec.surrey.ac.uk/ Research/SEEDS.htm

[7] Ettema, D. and Timmermans, H. (1997), Activity Based Approaches to Travel Analysis, Pergamon Press/Elsevier Science, UK. 
[8] Hensher, D., and Button, K. (2000) Handbook of Transport Modelling, Pergamon, Oxford.

[9] Hensher, D and Dalvi, Q. (1978), Determinants of Travel Choice, Saxon House, UK.

[10] Washington, S. (2000), Iteratively Specified Tree-Based Regression: Theory and Trip Generation Example, Journal of Transportation Engineering, 126(6), 482-491.

[11] Nelson, J. (1988), Household Economies of Scale in Consumption: Theory and Evidence, Econometrica, 56(6), pp1301-1314.

[12] NOMIS - Official Labour Market Statistics, Accessed via www.nomisweb.co.uk (2005).

[13] UK Census of Population (2001), Accessed via www.statistics.gov.uk.

[14] Baltagi, B. (2001) Econometric Analysis of Panel Data, John Wiley and Sons, UK.

[15] Planning Policy Guidance 13: Transport (PPG13) (2001), Office of the Deputy Prime Minister.

[16] Tan, Y. and Fan, H. (2003), Traffic Generated by Office and Retail developments in Singapore, Proceeding of the Institute of Civil Engineers: Transport 156(4), 189-99.

[17] Dasgupta, M., Raha, N. and Sharman, K. (1996), Review of Trip Generation Studies, TRL Report 190, Transportation Research Laboratory, UK. 